\title{
Estimation of Longitudinal Aerodynamic Derivatives Using Genetic Algorithm Optimized Method
}

\author{
Ambuj Srivastava ${ }^{1}$, Ajit Kumar ${ }^{2}$, Ajoy Kanti Ghosh ${ }^{2}$ \\ ${ }^{1}$ Transport Aircraft Research and Design Centre, Kanpur, India \\ ${ }^{2}$ Department of Aerospace Engineering, Indian Institute of Technology, Kanpur, India
}

Email address:

ambujs@iitk.ac.in (A. Srivastava)

\section{To cite this article:}

Ambuj Srivastava, Ajit Kumar, Ajoy Kanti Ghosh. Estimation of Longitudinal Aerodynamic Derivatives Using Genetic Algorithm Optimized Method. American Journal of Engineering and Technology Management. Vol. 4, No. 2, 2019, pp. 34-46. doi: 10.11648/j.ajetm.20190402.11

Received: April 10, 2019; Accepted: May 21, 2019; Published: June 10, 2019

\begin{abstract}
This paper presents the estimation of longitudinal aerodynamic parameters by using Genetic Algorithm (GA) optimized method from simulated and real flight data of ATTAS aircraft. The simulated flight data is deliberately contaminated with $5 \%, 10 \%$, and $15 \%$ of random noise for creating flight data, which bears similarity to real flight data. The proposed methodology utilizes the general notion of output error method, i.e., minimizing the response error between the measured response and estimated response, and the genetic algorithm as the optimization technique for an iterative update of the parameter vector. The longitudinal parameters are estimated by using the proposed method from both simulated data (without and with random noise) and real flight data. The parameter estimates obtained by using the proposed method is compared with the estimates from the Maximum-Likelihood method and data-driven methods viz. Delta method and GPR -Delta method for assessing the efficacy of the methodology. The statistical analysis of the parameter estimates has further cemented the confidence in the estimates obtained by using the proposed method.
\end{abstract}

Keywords: Genetic Algorithm, Parameter Estimation, Flight Dynamics, Aerodynamic Derivatives, Maximum Likelihood, Data-Driven Method

\section{Introduction}

The most generic definition of parameter estimation is the method of obtaining the most probable values of the aerodynamic derivatives, which are used to define the system itself. The parameter estimation is the subset of System Identification, which is a broader field including a comprehensive understanding of the underlying physical principle and determination of unknown stability and control derivatives [1-6]. The System Identification comprises of the postulation of all feasible mathematical models, choosing the most suitable model amongst all models, and the estimation of unknown parameters. The parameter estimation encompasses the determination of unknown parameters from a structured model by using Input-Output dataset. The aerodynamic parameters are required for a variety of purposes viz. generation of high fidelity database, development of flight simulators, extension, and validation of flight envelope, real-time fault detection, and repair [1, 7]. As mentioned earlier, that for the parameter estimation, the model is fixed so, the choice of the mathematical model is very crucial. The most critical portion of model postulation is the determination of a model for the estimation of aerodynamic forces, as they cannot be obtained directly. The scope of the mathematical model for the determination of aerodynamic forces is to devise suitable connections of forces $(X, Y, Z)$ and moments $(L, M, N)$ along the three axes in terms of translational motion variables $(\mathrm{u}, \mathrm{v}, \mathrm{w})$, rate of rotation $(\mathrm{p}, \mathrm{q}, \mathrm{r})$ and control surface deflections along the three axes [1].

The parameter estimation for aerospace problems had been attempted in the past by several methods, and each one is associated with their own merits and demerits. The analytical method, which forms its complete foundation on concepts of flight physics. The analytical methods express any system to a significant level of precision but entail a large number of inputs when having a complex nonlinear application. The unceasing developments in the pitch of computational assistance and enhanced expertise of computation notions and approaches, Computational Fluid Dynamics (CFD) has appeared as a competent method for the analytical parameter 
estimation of aerodynamic derivatives with advanced Euler and Navier-stokes flow solvers [3]. The experimental methods are essential to corroborate the estimates of analytical approaches. The wind tunnel method has the necessary restrictions viz. the simulation of control surface motion, accurate simulation of effects of power, simulation of propeller disc. The wind tunnel experiments bear undesirable effects of wind tunnel errors due to wake effect, Solid effect, turbulence \& swirl, and generation of flow-field similar to real flight conditions. That above circumstances demand the existence of another experimental method, which can meticulously mimic the real flight conditions, and thereby eliminates the requirement of dynamically similar flows. The above circumstances pave the path for the development of flight test method for substantiation of estimates made from analytical and wind tunnel experiments $[1,7,8,9]$.

The methods of parameter estimation, which use flight data for the parameter estimation, finds its traces since 1947 when Milliken [10] attempted to determine static and as well as the dynamic parameters of an aircraft. Similarly, Greenberg [11] and Shinbrot [12] presented a methodology inspired by ordinary non-linear least squares.

There are three categories of methods of parameter estimation [3], namely Equation Error Methods (EEM), Output Error Methods (OEM), and Filter Error Methods (FEM). The equation error method focus on making the parameter estimation problem as a linear one. The output error method and filter error method determine the parameters through a non-linear approach. The equation error method and output error method are categorized as the deterministic method, whereas, the filter error method as the stochastic one. The equation error method finds its basis on linear regression by employing the ordinary least squares method. The prime merit of the equation error method is computational easiness and absence of an iterative technique for parameter estimation. The significant demerits are asymptotic biasing behavior, erratic nature, and inappropriateness in the estimates when employed for parameter estimation with noisy measurement data [13]. The output error method gains the application to most of the parameter estimation problems, especially about flight vehicles. The output error method functions on the iterative adjustment of the parameter vector for which the response error between measured and estimated response is minimized. A kind of output error method, i.e., Maximum-Likelihood method focuses on estimating aerodynamic parameters through maximizing the probability density function of the observations $[1,13]$.

The focal benefit of the ML Method is that the parameter estimates possess the characteristics of asymptotic non-biasing, consistency, and efficiency. The ML method is capable of handling flight data with measurement noise and can adequately estimate aerodynamic parameters for any linear and nonlinear systems [1]. When the ML method is applied for parameter estimation from flight data measured in the presence of atmospheric turbulence, the output error method faces glitches in predicting precise estimates. It is imperative to mention that all flight-databased methods are prone to inconsistency if the quality of flight data is unreliable. In order to thwart the inconsistencies in the parameter estimates, it is advisable to employ instruments enabling exact measurement of motion and control variables. The additional crucial aspect is that the flight maneuvers for exciting the response of the aircraft must be executed with the correct procedure and in conditions with less atmospheric turbulence. However, it is pertinent to mention that it is incredibly impractical to meet both the requisites. It is always possible to reduce measurement noise by the use of appropriately designated and calibrated sensors. The process noise or error due to atmospheric turbulence is impossible to avoid absolutely. The obvious solution to this problem is to choose the filter error method, being a stochastic method it can handle measurement noise and as well as process noise [1, 14].

The methods mentioned above need a mathematical structure to solve equations of motion for offering the parameter estimates. In addition to these methods, some of the modern methods, which bear a foundation on heuristics, also achieved much of the success in parameter estimation. The vital difference is the non-requirement of the solution of equations of motion for delivering the parameter estimates. Some of the methods which are an integral part of this community are neural-network, fuzzy-logic, neuro-fuzzy, and genetic algorithm based methods. The methods, which are part of the community of data-driven methods, do experience the challenge of training the network and supplemental complexity during the genesis of logic [15-27].

In the present work, the Genetic Algorithm (GA) optimized output error method is used for longitudinal aerodynamic parameter estimation. The work delivers the usage of a method, which utilizes the vital knowledge of minimalizing the response error from the output error method and the genetic algorithm for repetitively modifying the parameter vector. The purpose is to establish that an exploration centered optimization technique is capable of estimating aerodynamic derivatives. The main reason for choosing genetic algorithm optimization is the absence of the necessary requirement of gradients. Nils Barricelli [28] spawned the most primitive genetic algorithm code, and his investigation was published in 1954. The software had the ability to imitate the course of biological reproduction and the mutation. Mitchell [29] places that John Holland [30, 31] perceived the exact arrangement of genetic algorithms, which is employed nowadays, in the 1960s. Holland's procedure [30, 31] encompasses impersonation of Darwin's theory of evolution, i.e., 'Survival of the Fittest,' and the practices of genetics, i.e., crossover, recombination, mutation, and inversion. The genetic algorithm is investigated for various aerospace applications, which includes the shape optimization of wing and aerofoil, real-time flight path planning, and even the drag estimation of aerostat [32-39]. The parameter estimates are obtained by using simulated data (with 5\%,10\% and 15\% random noise) and real flight test data of ATTAS aircraft. A comparative assessment of the longitudinal aerodynamic derivatives, which are determined from the proposed method, Maximum-Likelihood method, Delta method [16, 17] and GPR-Delta method [40] is prepared. 
The comparison of parameter estimates, together with statistical analysis evidence that the proposed GA optimized output error method can be utilized as a potential method for parameter estimation.

The paper offers:

(1) Development of a genetic algorithm optimized model for the estimation of longitudinal aerodynamic parameters.

(2) The statistical analysis of the parameter estimates by using the proposed method from both simulated (With 5\%, $10 \%$, and $15 \%$ random noise) and real flight data.

(3) The comparative assessment of the parameter estimates with the popular conventional ML method and data-driven methods.

The subsequent units present the description about longitudinal dynamics and parameters of the aircraft, GA optimized output error method, Parameter estimates, comparative assessment with other methods along with discussion, and finally the conclusions drawn from the present work.

\section{Longitudinal Dynamics and the Parameters of the Aircraft}

The longitudinal flight maneuvers are oriented to excite the short period pitch oscillation (SPPO) and not the long period ones, i.e., Phugoid mode. The estimation of dimensionless longitudinal aerodynamic parameters utilizes state equations for postulating the linear aerodynamic model [1].

$$
\begin{gathered}
\dot{V}=-\frac{q^{-} S}{m} \cdot C_{D}+g \sin (\alpha-\theta)+\frac{F_{e}}{m} \cos \left(\alpha+\sigma_{T}\right) \\
\alpha=-\frac{\bar{q} S}{m} C_{L}+\frac{g}{V} \cos (\alpha-\theta)-\frac{F_{e}}{m V} \sin \left(\alpha+\sigma_{T}\right) \\
\theta \dot{=} q \\
q=\frac{\bar{q} s \bar{c}}{I_{y}} C_{m}+\frac{F_{e}}{I_{y}}\left(l_{t x} \sin \alpha_{T}+l_{t z} \cos \sigma_{T}\right)
\end{gathered}
$$

The non-dimensional longitudinal aerodynamic coefficients $C_{D}, C_{L}$ and $C_{m}$ are modelled in terms of longitudinal aerodynamic parameters $[1,41]$. The objective is to determine these aerodynamic parameters.

$$
\begin{gathered}
C_{D}=C_{D 0}+C_{D \alpha} \alpha+C_{D \delta e} \delta e \\
C_{L}=C_{L 0}+C_{L \alpha} \alpha+C_{L q}\left(\frac{q \bar{c}}{2 V}\right)+C_{L \delta e} \delta e \\
C_{m}=C_{m 0}+C_{m \alpha} \alpha+C_{m q}\left(\frac{q \bar{c}}{2 V}\right)+C_{m \delta e} \delta e
\end{gathered}
$$

The overall objective of the present work is to estimate the parameter vector i.e. $\Theta$.

$$
\Theta=\left[C_{D 0} C_{D \alpha} C_{D \delta e} C_{L 0} C_{L \alpha} C_{L \delta e} C_{L q} C_{m 0} C_{m \alpha} C_{m \delta e} C_{m q}\right]^{T}
$$

The $C_{D \delta e}, C_{L \delta e}$ and $C_{m \delta e}$ are the aerodynamic parameters, which are effected by the movement of the elevator and hence are known as the control parameters. The $C_{D 0}, C_{D \alpha}, C_{L 0}, C_{L \alpha}, C_{m 0}, C_{m \alpha}$ are the aerodynamic parameters, which are effected by the primary motion variable, i.e., the angle of attack. These aerodynamic parameters directly affect the stability of the aircraft, and hence known as the stability parameters. In addition to these parameters, the $C_{L q}$ and $C_{m q}$ are also stability parameters, which are affected by the pitch rate of the aircraft.

\section{Methodology}

The popular output error method, i.e., the ML method uses the general notion of output error method, i.e., minimizing response error, and the gradient-based optimization technique Gauss-Newton or Levenberg-Marquardt for the iterative update of the parameter vector. The gradient-based methods require the computation of the first and second gradients of the objective function. When the search space is small, and for the primary objective function, the gradient-based optimization methods result in a globally optimum solution. When a flight vehicle with complex system dynamics undergoes a flight phase where non-linearity prevails, then the resulting objective function is expected to be an intricate one. In such circumstances, the parameter estimation through gradient-based optimization strategy will experience computation difficulties regarding computation of gradients, especially second gradients. It will incur high computation liability and may even limit the estimation of parameters itself.

In order to avoid such a situation, there is a requirement of optimization strategy, which does not necessitate such a computational burden. The genetic algorithm optimization is capable of providing an efficient mode of estimating aerodynamic parameters. The merits like the capability of predicting several optimum solutions rather than a single solution, possible scope of improvement in the estimates, and non-requirement of computation of gradients and many more, establishes this as a useful optimization tool.

When longitudinal aerodynamic parameters are estimated from simulated data, the aerodynamic forces and moment coefficients employ equation 5-7 for obtaining their values. The stability and control derivatives appearing in the equation assume their wind tunnel values. On the contrary, while estimating aerodynamic parameters from real flight data, the longitudinal aerodynamic force and moment coefficients are obtained by using equations $9-13$. The response error between the measured response and the computed response is computed by using equation 14, and the cost function for the parameter estimation is given by equation 15 .

$$
\begin{gathered}
C_{L}=-C z \cos \alpha+C x \sin \alpha \\
C_{D}=-C x \cos \alpha-C z \sin \alpha \\
C m=\frac{\left[I_{y} \dot{q}+I_{x z}\left(p^{2}-r^{2}\right)-\left(I_{z}-I_{x}\right) p r\right]}{\bar{q} s \bar{c}} \\
C z=\frac{m a_{z}}{\bar{q} S_{r e f}} \\
C x=\frac{\left(m a_{x}-T\right)}{\bar{q} S_{r e f}}
\end{gathered}
$$




$$
\begin{gathered}
e=Z-Y \\
Y_{\text {cost }}=0.5 \sqrt{\sum e^{2}}
\end{gathered}
$$

Where $a_{z} \& a_{x}$ are acceleration along $\mathrm{z}$ and $\mathrm{x}$ axes respectively. $\mathrm{m}=$ mass of a/c, $\bar{q}=$ dynamic pressure, $\mathrm{S}_{\text {ref }}=$ wing reference area, $\mathrm{T}=$ Thrust, $\mathrm{V}=$ True airspeed, $\alpha=$ Angle of Attack $=$ pitch rate, $\delta \mathrm{e}=$ Elevator deflection, $F_{e}=$ Thrust from the engine, $\sigma_{T}=$ Inclination angle of engines, $\bar{c}=$ Mean aerodynamic chord of the wing, $I_{y}=$ Moment of Inertia about $y$-axis, $\rho=$ density of air,

The methodology is to repeatedly run the GA optimized algorithm with the same flight data and initial values. The genetic algorithm predicts a new optimum solution at the end of every run of the GA optimized algorithm. The proposed methodology is made to predict 20 number of optimum solutions, and the final value is obtained after statistical analysis including, mean value, standard deviation, standard error and coefficient of determination $\left(\mathrm{R}^{2}\right)$. The scatter plots of various aerodynamic parameters are made to demonstrate the dispersion in the estimates about the mean value.

\section{Longitudinal Parameter Estimation}

\subsection{Parameter Estimation by Using Simulated Flight Data}

The longitudinal aerodynamic parameters are estimated by using the proposed methodology firstly from simulated flight data without noise. The subsequent step is the parameter estimation when simulated flight data is intentionally contaminated with $5 \%, 10 \%$ and $15 \%$ of random noise in measurement variable, i.e., the angle of attack. The intention is to create practical flight conditions, as the real flight is inevitably contaminated with measurement noise in the motion variables. The parameter estimates are presented in Table 1, the scatter plots of the estimated concerned aerodynamic parameters are given in Figure 1.

\begin{tabular}{|c|c|c|c|c|c|c|}
\hline \multicolumn{7}{|c|}{ Longitudinal Parameters of ATTAS aircraft (Simulated data $-0 \%$ noise) } \\
\hline S.No & Parameter & Noise characteristic & OEM with GA & Standard deviation (SD) & Standard Error & $\mathbf{R}^{2}$ \\
\hline 1 & $\mathrm{C}_{\mathrm{D} 0}$ & NIL & 0.0399 & 0.0036 & 0.0008 & 0.9028 \\
\hline 2 & $\mathrm{C}_{\mathrm{D} \alpha}$ & NIL & 0.2611 & 0.0033 & 0.0007 & 0.9252 \\
\hline 3 & $\mathrm{C}_{\mathrm{L} 0}$ & NIL & 0.2354 & 0.0325 & 0.0072 & 0.9124 \\
\hline 4 & $\mathrm{C}_{\mathrm{L} \alpha}$ & NIL & 5.2500 & 0.0274 & 0.0068 & 0.9358 \\
\hline 5 & $\mathrm{C}_{\mathrm{L} \delta \mathrm{e}}$ & NIL & 0.2072 & 0.0014 & 0.0003 & 0.8882 \\
\hline 6 & $\mathrm{C}_{\mathrm{m} 0}$ & NIL & 0.0803 & 0.0193 & 0.0043 & 0.9411 \\
\hline 7 & $\mathrm{C}_{\mathrm{m} \alpha}$ & NIL & -0.8676 & 0.0028 & 0.0006 & 0.8879 \\
\hline 8 & $\mathrm{C}_{\mathrm{m \delta e}}$ & NIL & -0.9879 & 0.0065 & 0.0015 & 0.9078 \\
\hline 9 & $\mathrm{C}_{\mathrm{mq}}$ & NIL & 5.8156 & 0.2298 & 0.0530 & 0.7949 \\
\hline
\end{tabular}

Table 1. Longitudinal Parameters of ATTAS aircraft (Simulated data $-0 \%$ noise).
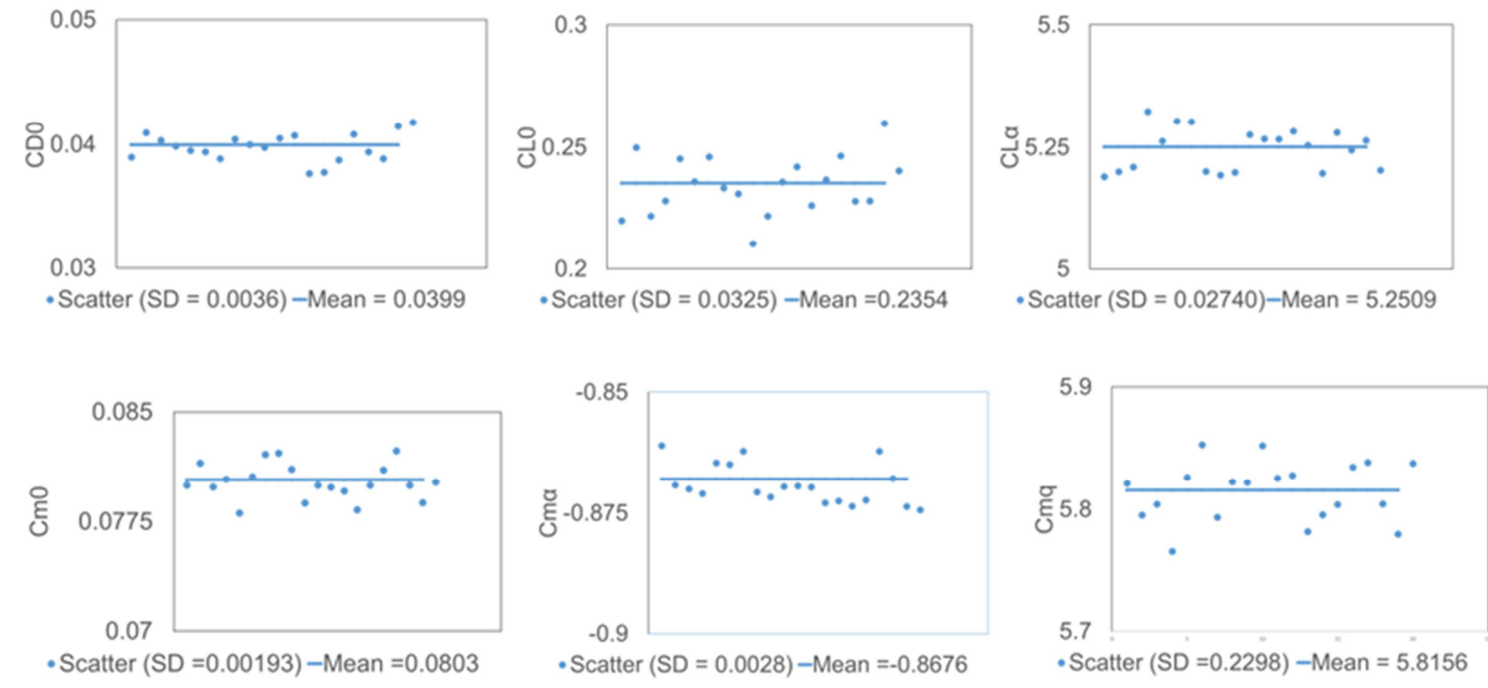

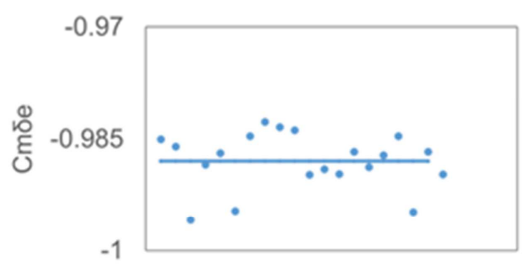

- Scatter $(\mathrm{SD}=0.00653)-$ Mean $=-0.9879$

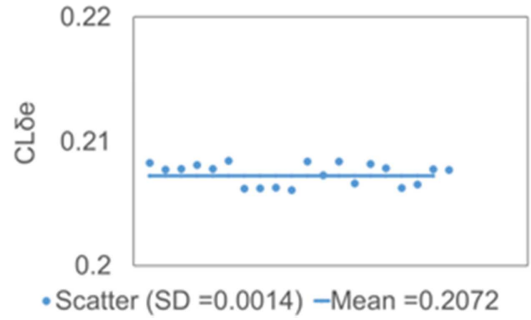

- Scatter $(S D=0.0014)-$ Mean $=0.2072$

Figure 1. Scatter plots of longitudinal aerodynamic parameters - ATTAS aircraft (Simulated-0\%). 
The estimated aerodynamic parameters exhibit appreciable consistency and statistical analysis. The standard deviation of all aerodynamic parameters ranges between a minimum of 0.0014 for $\mathrm{C}_{\mathrm{L} \delta \mathrm{e}}$ to a maximum of 0.2298 for $\mathrm{C}_{\mathrm{mq}}$. The standard error ranges from a minimum value of 0.0003 for $\mathrm{C}_{\mathrm{L} \delta \mathrm{e}}$ to a maximum of 0.0530 for $\mathrm{C}_{\mathrm{mq}}$. The coefficient of determination $\left(\mathrm{R}^{2}\right)$ follows a range from the least value of 0.7949 for $\mathrm{C}_{\mathrm{mq}}$ to highest value of 0.9411 for $C_{m 0}$. The $C_{m q}$ is a weak longitudinal aerodynamic parameter, which negligibly affects the aircraft motion. The inconsistent behavior of $\mathrm{C}_{\mathrm{mq}}$ can be accredited to probable reasons like $\mathrm{C}_{\mathrm{mq}}$ is a weak parameter, and hence, it is difficult to estimate by any of the known methods of parameter estimation, and the simulated flight data might not be appropriate for a more consistent estimate. The scatter plots depict the mean value and standard deviation of the respective aerodynamic parameter. The scatter plot of

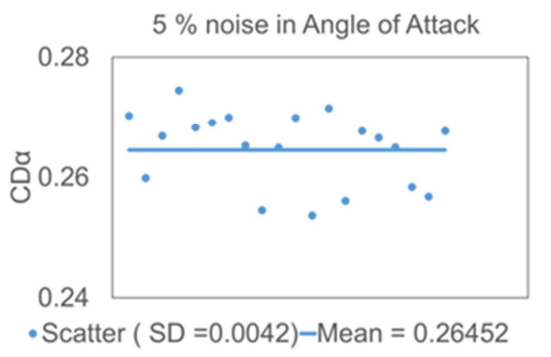

several aerodynamic parameters also indicate that all the optimum estimates exhibit a significantly low dispersion about the mean value and lie within $3 \sigma$ deviation. The scatter plots of longitudinal aerodynamic parameters exhibit a significantly low dispersion about the mean value.

The following task is to estimate the longitudinal aerodynamic parameters estimates from the simulated flight data contaminated with $5 \%, 10 \%$ and $15 \%$ noise in the motion variable, i.e., the angle of attack. The parameters, which are affected by noise in the angle of attack, will be only $\mathrm{C}_{\mathrm{D} \alpha}, \mathrm{C}_{\mathrm{L} \alpha}$, and $\mathrm{C}_{\mathrm{m} \alpha}$. The parameter estimates from simulated flight data with $5 \%, 10$, and $15 \%$ noise are presented in Table 2 - Table 4 , respectively. The scatter plots of relevant aerodynamic parameters, which experience variation due to noise in the angle of attack, are presented in Figure 2-Figure 4, respectively.
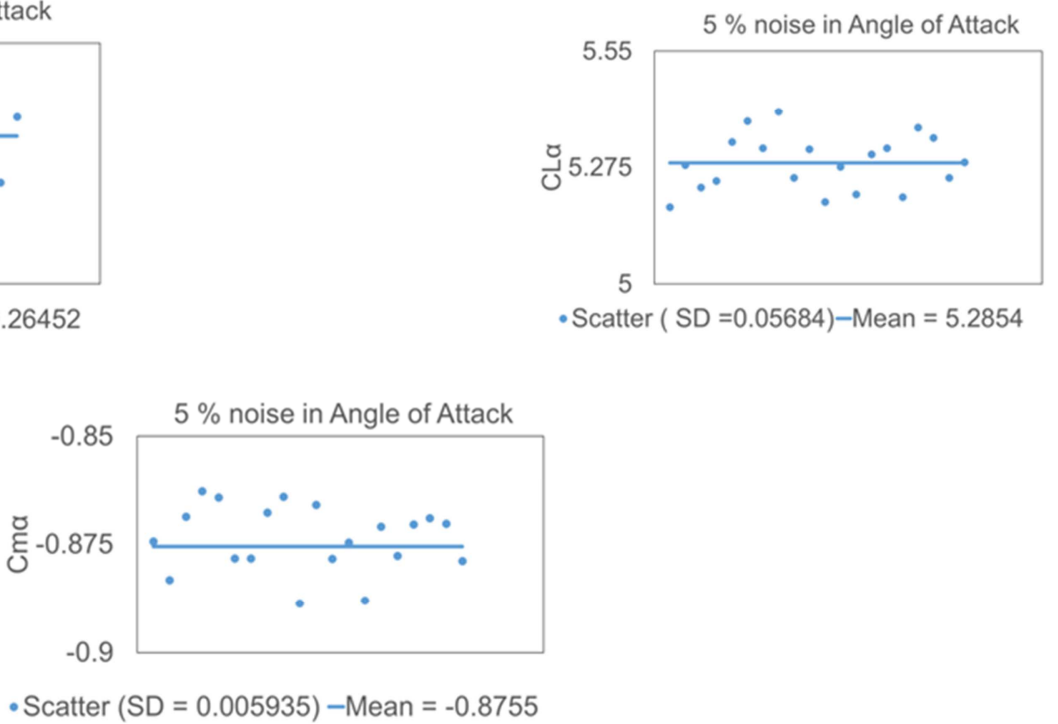

Figure 2. Scatter plots of longitudinal aerodynamic parameters - ATTAS aircraft (Simulated-5\%).
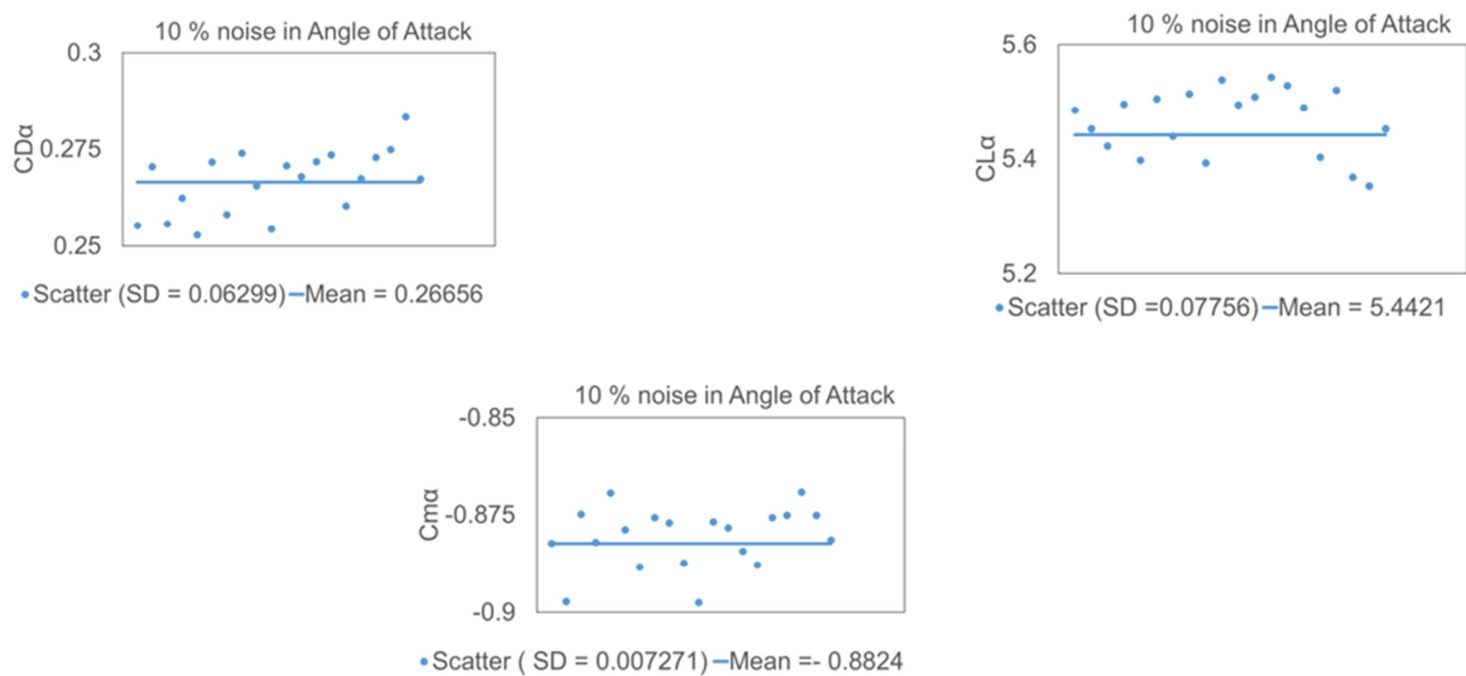

Figure 3. Scatter plots of longitudinal aerodynamic parameters - ATTAS aircraft (Simulated-10\%). 
Table 2. Longitudinal Parameters of ATTAS aircraft (Simulated data $-5 \%$ noise).

\begin{tabular}{lllllll}
\hline \multicolumn{2}{l}{ Longitudinal } & Parameters of ATTAS aircraft (Simulated data $\mathbf{- 5 \%}$ noise) & & & \\
\hline S.No & Parameter & Noise characteristic & OEM with GA & Standard deviation (SD) & Standard Error & $\mathbf{R}^{\mathbf{2}}$ \\
\hline 1 & $\mathrm{C}_{\mathrm{D} \alpha}$ & $5 \%$ in $\alpha$ & 0.2645 & 0.0042 & 0.0009 & 0.9067 \\
2 & $\mathrm{C}_{\mathrm{L} \alpha}$ & $5 \%$ in $\alpha$ & 5.2854 & 0.0568 & 0.0127 & 0.9358 \\
3 & $\mathrm{C}_{\mathrm{m} \alpha}$ & $5 \%$ in $\alpha$ & -0.8755 & 0.0059 & 0.0013 & 0.8773 \\
\hline
\end{tabular}

Table 3. Longitudinal Parameters of ATTAS aircraft (Simulated data $-10 \%$ noise).

\begin{tabular}{lllllll}
\hline \multicolumn{2}{l}{ Longitudinal Parameters of ATTAS aircraft (Simulated data $-\mathbf{1 0} \%$ noise) } & & & \\
\hline S.No & Parameter & Noise characteristic & OEM with GA & Standard deviation (SD) & Standard Error & R2 \\
\hline 1 & $\mathrm{C}_{\mathrm{D} \alpha}$ & $10 \%$ in $\alpha$ & 0.2666 & 0.0063 & 0.0014 & 0.9281 \\
2 & $\mathrm{C}_{\mathrm{L} \alpha}$ & $10 \%$ in $\alpha$ & 5.4421 & 0.0776 & 0.0173 & 0.9112 \\
3 & $\mathrm{C}_{\mathrm{m} \alpha}$ & $10 \%$ in $\alpha$ & -0.8824 & 0.0073 & 0.0016 & 0.8821 \\
\hline
\end{tabular}

Table 4. Longitudinal Parameters of ATTAS aircraft (Simulated data -15\% noise).

\begin{tabular}{lllllll}
\hline \multicolumn{2}{l}{ Longitudinal Parameters of ATTAS aircraft (Simulated data $\mathbf{- 1 5} \%$ noise) } & & & \\
\hline S.No & Parameter & Noise characteristic & OEM with GA & Standard deviation (SD) & Standard Error & $\mathbf{R}^{2}$ \\
\hline 1 & $\mathrm{C}_{\mathrm{D} \alpha}$ & $15 \%$ in $\alpha$ & 0.2875 & 0.0053 & 0.0012 & 0.9013 \\
2 & $\mathrm{C}_{\mathrm{L} \alpha}$ & $15 \%$ in $\alpha$ & 5.5100 & 0.0829 & 0.0185 & 0.9043 \\
3 & $\mathrm{C}_{\mathrm{m} \alpha}$ & $15 \%$ in $\alpha$ & -0.8398 & 0.0055 & 0.0012 & 0.8792 \\
\hline
\end{tabular}
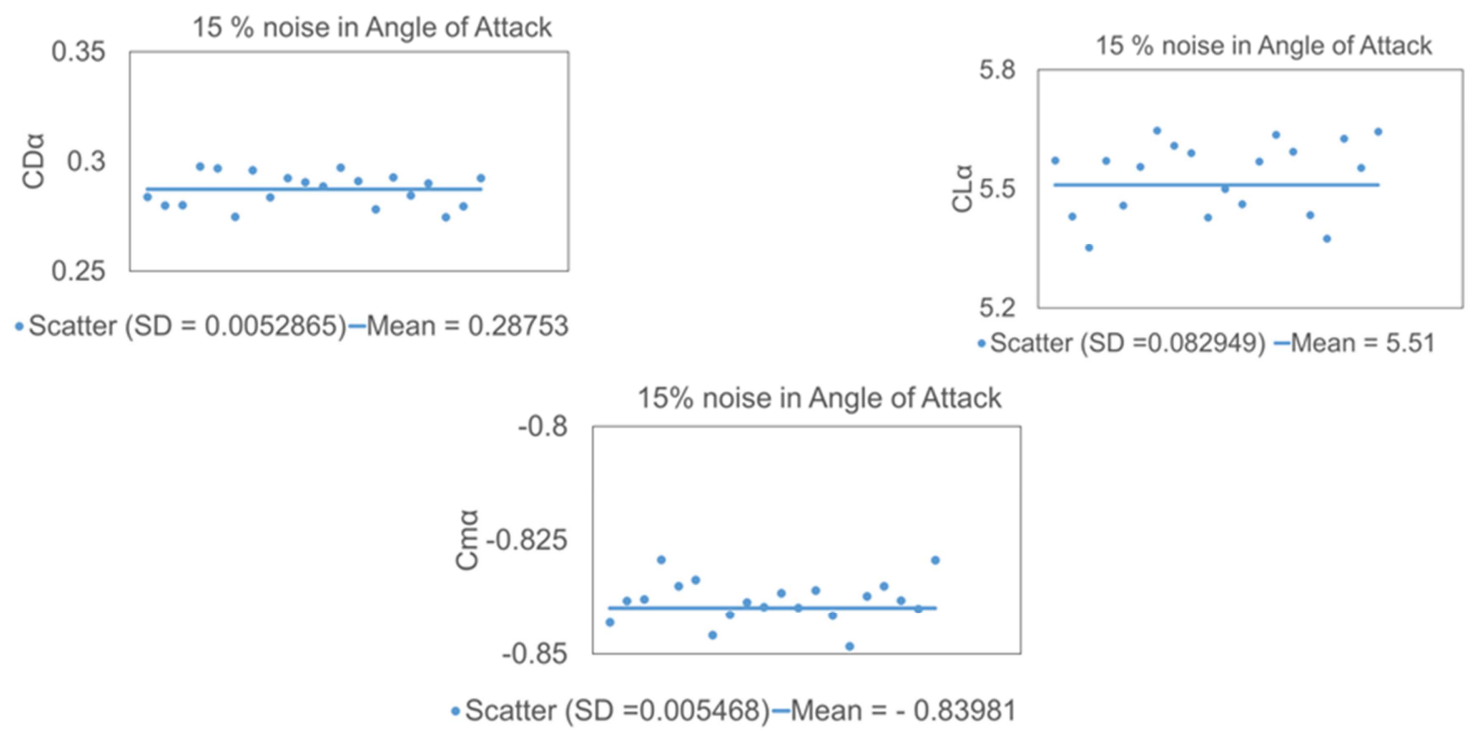

Figure 4. Scatter plots of longitudinal aerodynamic parameters - ATTAS aircraft (Simulated-15\%).

For $5 \%$ random noise in the angle of attack, the standard deviation of estimates exists within a minimum of 0.0042 for $\mathrm{C}_{\mathrm{D} \alpha}$ to a maximum of 0.0568 for $\mathrm{C}_{\mathrm{L} \alpha}$. The standard error bears the similar behavior, i.e., from a minimum of 0.0009 for $\mathrm{C}_{\mathrm{D} \alpha}$ to a maximum of 0.0127 for $\mathrm{C}_{\mathrm{L} \alpha}$. The coefficient of determination $\left(\mathrm{R}^{2}\right)$ lies from 0.8773 to 0.9358 , which is much high to boost confidence in the parameter estimates. The parameter estimates with $10 \%$ noise in the angle of attack show that the standard deviation of estimates exists from a minimum of 0.0063 for $\mathrm{C}_{\mathrm{D} \alpha}$ to a maximum of 0.0776 for $\mathrm{C}_{\mathrm{L} \alpha}$. The standard error apes the trend, i.e., from a minimum of 0.0014 for $C_{D \alpha}$ to a maximum of 0.0173 for $C_{L \alpha}$. The coefficient of determination $\left(\mathrm{R}^{2}\right)$ spans from 0.8821 to 0.9112 , which is significant for the credibility of the parameter estimates. The parameter estimates with $15 \%$ noise in the angle of attack also display a similar trend, which exists for estimates with lower noise. The standard deviation of estimates ranges from a minimum of 0.0053 for $\mathrm{C}_{\mathrm{D} \alpha}$ to a maximum of 0.0829 for $\mathrm{C}_{\mathrm{L} \alpha}$. The standard error displays a minimum of 0.0012 for $C_{D \alpha}$ to a maximum of 0.0185 for $C_{L \alpha}$. The coefficient of determination $\left(\mathrm{R}^{2}\right)$ ranges from 0.8792 to 0.9043 , which is significant for the credibility of the parameter estimates. It is crucial to appreciate that $\mathrm{C}_{\mathrm{D} \alpha}$ and $\mathrm{C}_{\mathrm{L} \alpha}$ are robust longitudinal aerodynamic parameters, which noticeably touches the longitudinal motion of aircraft. The erratic behavior of $\mathrm{C}_{\mathrm{D} \alpha}$ and $\mathrm{C}_{\mathrm{L} \alpha}$ can be endorsed to the random nature of noise in the simulated flight data, which spoiled the proper estimation of aerodynamic derivatives by the proposed method.

\subsection{Parameter Estimation by Using Real Flight Data}

The proposed methodology could predict parameter estimates with robust statistical analysis. The statistical analysis has boosted the confidence towards the application of 
the proposed methodology for parameter estimation from real flight data. A comparative assessment of the parameter estimates from simulated and real flight data will further strengthen the reliability of the proposed methodology. The flight test data of ATTAS aircraft for the flight maneuver enabling short-period oscillations is available in the database of Jategaonkar [1]. The measured value of output variable, i.e., non-dimensional aerodynamic force and moment are obtained through principles of flight physics expressed in the form of analytical equations 9-13. The motion variables and other variables, including control surface deflection, are measured during the time history response of the aircraft. The estimated longitudinal force and moment coefficients are obtained by using relevant equations, which describe the motion about the longitudinal stability axis in terms of longitudinal aerodynamic parameters, i.e., equation 5-7. The longitudinal aerodynamic parameters estimates are projected after the statistical analysis over 20 optimum solutions. The time history plot of motion variables is presented in Figure 5.
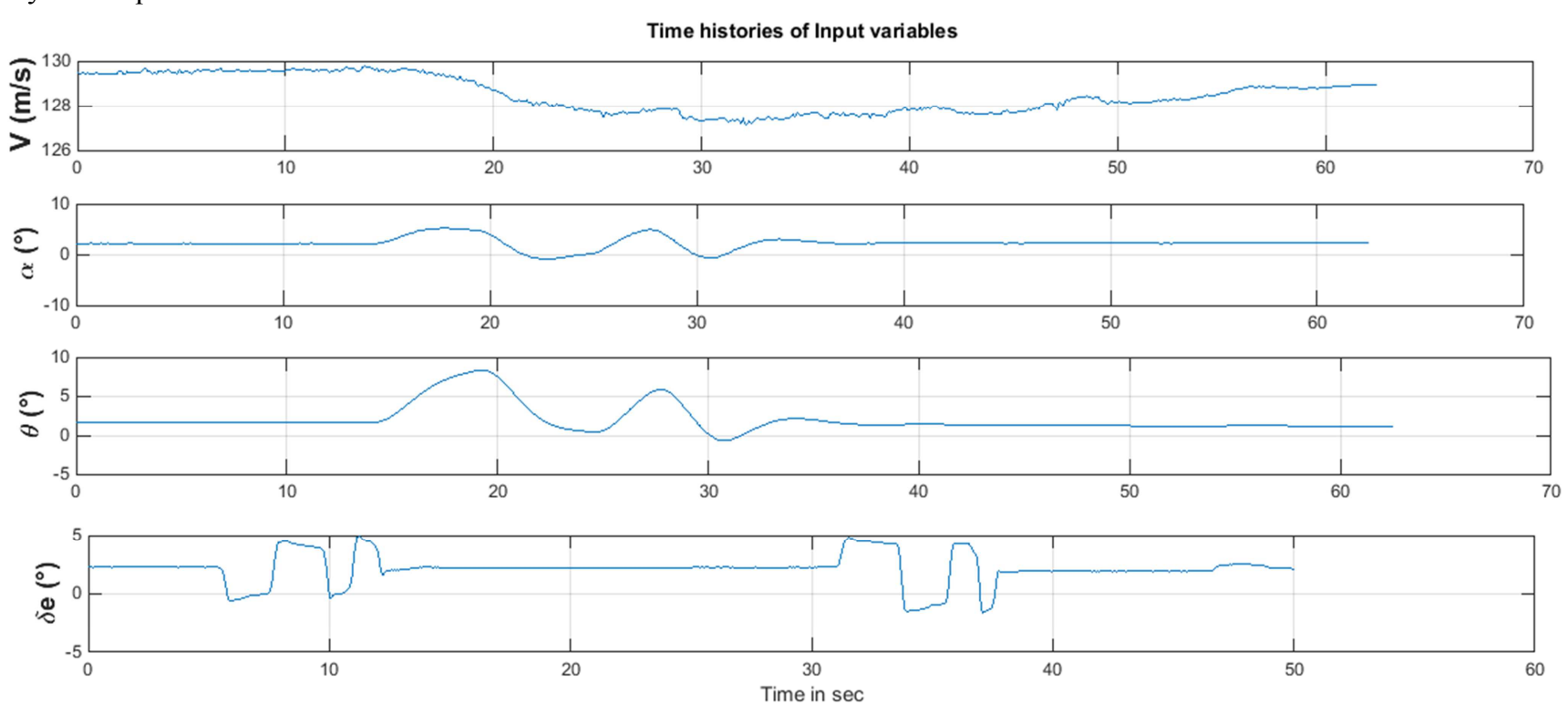

Figure 5. Flight test data (Real) of ATTAS aircraft.

The estimation of longitudinal aerodynamic parameters by using real flight data is attempted to provide a sort of corroboration to the estimated aerodynamic parameters through simulated flight data. The longitudinal parameter estimates thus obtained with the flight test data (Real) are presented in Table 5, and the scatter plots of the estimated concerned aerodynamic parameters are given in Figure 6

Table 5. Longitudinal Parameters of ATTAS aircraft (Real flight data).

\begin{tabular}{|c|c|c|c|c|c|}
\hline S.No & Parameter & OEM with GA & Standard deviation (SD) & Standard Error & $\mathbf{R}^{2}$ \\
\hline 1 & $\mathrm{C}_{\mathrm{D} 0}$ & 0.0408 & 0.0036 & 0.0008 & 0.9200 \\
\hline 2 & $\mathrm{C}_{\mathrm{D} \alpha}$ & 0.2613 & 0.0033 & 0.0007 & 0.9043 \\
\hline 3 & $\mathrm{C}_{\mathrm{L} 0}$ & 0.2352 & 0.0323 & 0.0072 & 0.9243 \\
\hline 4 & $\mathrm{C}_{\mathrm{L} \alpha}$ & 5.2625 & 0.2744 & 0.0613 & 0.9425 \\
\hline 5 & $\mathrm{C}_{\mathrm{L} \delta \mathrm{e}}$ & 0.2068 & 0.0137 & 0.0031 & 0.8518 \\
\hline 6 & $\mathrm{C}_{\mathrm{m} 0}$ & 0.0809 & 0.0193 & 0.0043 & 0.9691 \\
\hline 7 & $\mathrm{C}_{\mathrm{m} \alpha}$ & -0.8724 & 0.0281 & 0.0063 & 0.9127 \\
\hline 8 & $\mathrm{C}_{\mathrm{m \delta e}}$ & -0.9821 & 0.0652 & 0.0146 & 0.9298 \\
\hline 9 & $\mathrm{C}_{\mathrm{mq}}$ & 5.8017 & 0.2372 & 0.0530 & 0.6548 \\
\hline
\end{tabular}

The estimated longitudinal aerodynamic parameters display generous reliability and proper statistical investigation, even when real flight data is used. The scatter plots of corresponding aerodynamic parameter too direct to the element that all the optimum estimates lie within $3 \sigma$ deviation. The scatter plots demonstrate the mean value and standard deviation of the individual aerodynamic parameter. The standard deviation of all aerodynamic parameters lies within a minimum of 0.0033 for $\mathrm{C}_{\mathrm{D} \alpha}$ to a maximum of 0.2372 for $\mathrm{C}_{\mathrm{mq}}$. The standard error ranges from a minimum value of 0.0007 for $\mathrm{C}_{\mathrm{D} \alpha}$ to a maximum of 0.5304 for $\mathrm{C}_{\mathrm{mq}}$. The coefficient of determination $\left(\mathrm{R}^{2}\right)$ spans between the least value of 0.6548 for $\mathrm{C}_{\mathrm{mq}}$ to the highest value of 0.9691 for $\mathrm{C}_{\mathrm{m} 0}$. The educational background states that $\mathrm{C}_{\mathrm{mq}}$ is a weak longitudinal aerodynamic parameter, which negligibly affects the aircraft motion. The erratic behavior of $\mathrm{C}_{\mathrm{mq}}$ can be attributed to the constraint of any known method, which permits a precise and dependable estimate of weak parameters. Moreover, the real flight data might not be suitable for a more reliable estimate. The scatter plots of longitudinal aerodynamic parameters presented in Figure 6 display a considerably low dispersal about the mean value. 

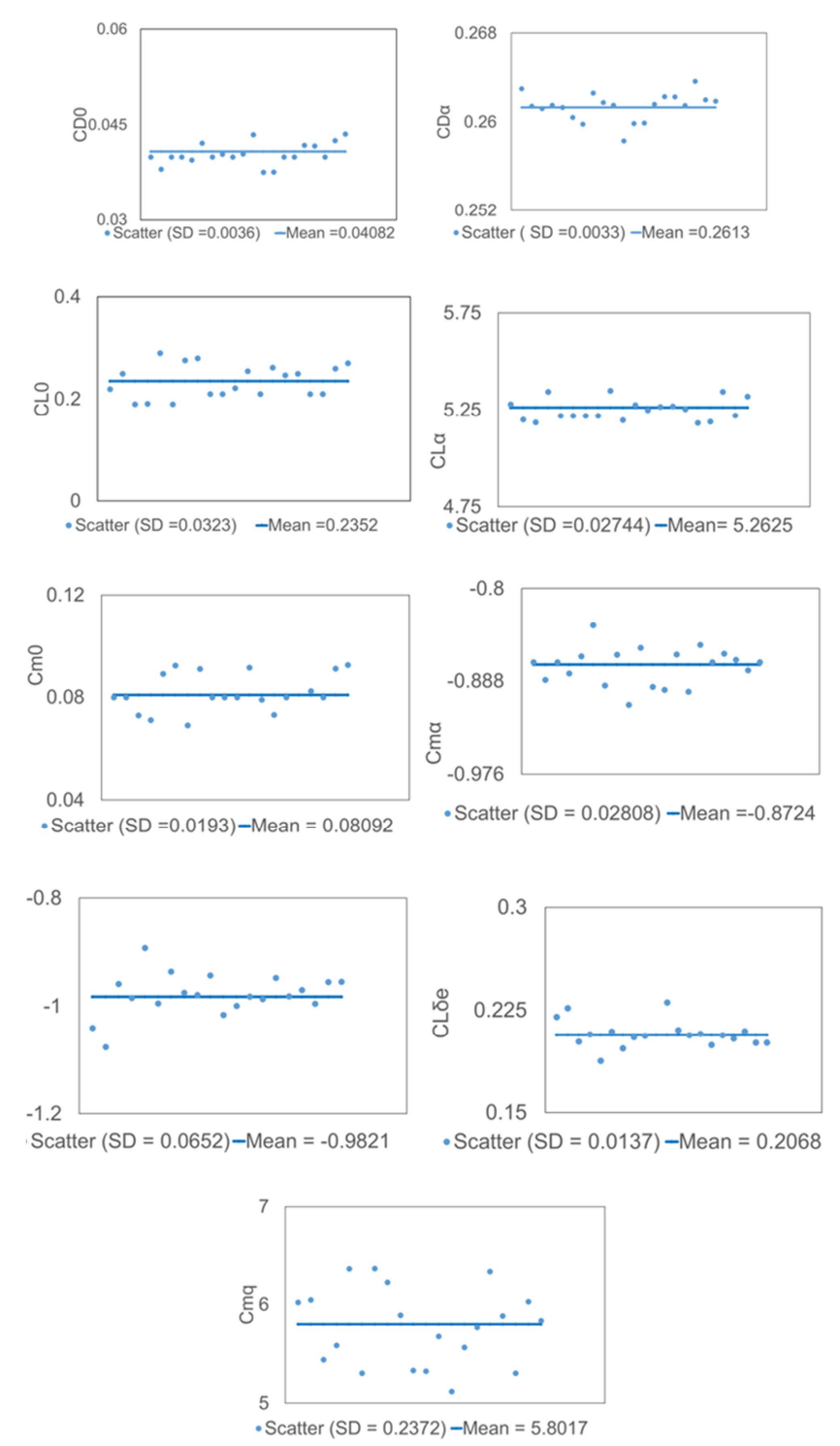

Figure 6. Scatter plots of longitudinal aerodynamic parameters - ATTAS aircraft (Real flight data).

\section{Comparative Assessment and Discussion}

\subsection{Comparison of Longitudinal Aerodynamic Parameters by Using Simulated Flight Data Without Noise and Real Flight Data}

A comparative assessment of the estimates of longitudinal aerodynamic parameters by using the proposed GA optimized output error method from real flight data and simulated flight data without noise is prepared. The primary purpose is to assess the GA optimized output error method for the longitudinal aerodynamic parameter estimation. Table 5.21 present the comparison of longitudinal aerodynamic parameters for the ATTAS aircraft considered in present work.

Table 6. Comparison of Longitudinal Parameters of ATTAS aircraft (Real flight data and simulated flight data).

\begin{tabular}{llll}
\hline \multicolumn{3}{l}{ Longitudinal aerodynamic parameters- ATTAS aircraft } \\
\hline \multirow{2}{*}{ S.No } & \multirow{2}{*}{ Parameter } & $\begin{array}{l}\text { OEM with GA } \\
\text {-Real flight data }\end{array}$ & $\begin{array}{l}\text { OEM with GA -Simulated } \\
\text { flight data W/o noise }\end{array}$ \\
\hline 1 & $\mathrm{C}_{\mathrm{D} 0}$ & 0.0408 & 0.0399 \\
2 & $\mathrm{C}_{\mathrm{D} \alpha}$ & 0.2613 & 0.2611 \\
3 & $\mathrm{C}_{\mathrm{L} 0}$ & 0.2352 & 0.2354 \\
4 & $\mathrm{C}_{\mathrm{L} \alpha}$ & 5.2625 & 5.2500 \\
5 & $\mathrm{C}_{\mathrm{L} \delta \mathrm{e}}$ & 0.2068 & 0.2072 \\
6 & $\mathrm{C}_{\mathrm{m} 0}$ & 0.0809 & 0.0803 \\
7 & $\mathrm{C}_{\mathrm{m} \alpha}$ & -0.8724 & -0.8676 \\
8 & $\mathrm{C}_{\mathrm{m} \delta \mathrm{e}}$ & -0.9821 & -0.9879 \\
9 & $\mathrm{C}_{\mathrm{mq}}$ & 5.8017 & 5.8156 \\
\hline
\end{tabular}

The evaluation of longitudinal aerodynamic parameters estimated by using proposed GA optimized output error method from real flight data and simulated flight data is envisioned to perceive the outcome of using noisy data and different models for obtaining a measured value of output variables, i.e., non-dimensional force and moment coefficients. This assessment permits to check the competence of the proposed GA optimized output error method towards the management of different models for real flight test data and simulated flight data. The estimates of all aerodynamic parameters by using real flight data are observed to be in decent agreement with the estimates obtained from simulated flight data. The evaluation of the parameter estimates clues that the proposed methodology can commendably handle both real flight data and simulated flight data for parameter estimation. The later phase involves the validation of the proposed methodology when simulated flight data is contaminated with random noise. The aim is to assess whether the proposed methodology can effectively handle measurement noise or not. As mentioned earlier that random nose of $5 \%, 10 \%$, and $15 \%$ is introduced only to the angle of attack so, the comparison of estimated stability and control derivatives, which are affected by the noise in the angle of attack, will additionally validate the ability of the proposed methodology. The stability and control derivatives affected by the noise in the angle of attack are $\mathrm{C}_{\mathrm{D} \alpha}, \mathrm{C}_{\mathrm{L} \alpha}$, and $\mathrm{C}_{\mathrm{m} \alpha}$. Table 7 presents the comparison of affected longitudinal aerodynamic parameters for the ATTAS aircraft.

Table 7. Comparison of longitudinal parameters of ATTAS aircraft.

\begin{tabular}{lllllll}
\hline \multicolumn{6}{l}{ Comparison of longitudinal aerodynamic parameters - ATTAS aircraft } \\
\hline \multirow{2}{*}{ S.No } & \multirow{2}{*}{ Parameter } & Real Flight data & Simulated Flight data & & & \\
\cline { 2 - 7 } & & OEM with GA & OEM with GA (W/o noise) & OEM with GA (5\%) & OEM with GA (10\%) & OEM with GA (15\%) \\
\hline 1 & $\mathrm{C}_{\mathrm{D} \alpha}$ & 0.2613 & 0.261068 & 0.26452 & 0.26656 & 0.28753 \\
2 & $\mathrm{C}_{\mathrm{L} \alpha}$ & 5.2625 & 5.25 & 5.2854 & 5.4421 & 5.51 \\
3 & $\mathrm{C}_{\mathrm{m} \alpha}$ & -0.8724 & -0.8676 & -0.8755 & -0.8824 & -0.83981 \\
\hline
\end{tabular}


The three stability and control derivatives exhibit slight variation from their counterpart estimated from without noise, but no specific trend is observed. The aerodynamic derivatives affected by noise in the angle of attack, strongly influence the longitudinal motion of aircraft. The evaluation tells that the proposed methodology of GA optimized output error method can predict the longitudinal aerodynamic parameters with decent consistency and precision from noisy flight data also. The respectable consistency in the estimates is due to the robustness of the proposed methodology such that it alleviates the effect of random noise. The nature of the noise is random, so noise level up to $15 \%$ could produce only minor addition for some estimates and a slight decrease for other estimates. However, there is no large slip in the values of estimates, when compared to estimates without noise.

\subsection{Comparison of Longitudinal Aerodynamic Parameters with Estimates Obtained from Other Methods}

As mentioned earlier, in present work, longitudinal aerodynamic parameters are estimated by using the proposed GA optimized output error method. The parameters are also estimated by using other existing methods such as the Maximum Likelihood (ML) method, the data-driven methods, i.e., Delta method [16, 17] and GPR-Delta [40] method. The parameters are estimated from both simulated data (Without and with random noise) and real flight data. The current unit will add an evaluation of parameter estimates achieved by the proposed GA optimized output error method and by other methods stated above. The other existing methods of parameter estimation deliberated in the present work use the same flight data both simulated (without and with noise) and as well as real flight data. The ML method uses the same mathematical models for simulated and real flight data, which are used by the proposed method, i.e., equation 5-7 for simulated data and equation 9-13 for real flight data. The ML method uses two gradient-based optimization technique, i.e., Gauss-Newton and Levenberg-Marquardt. The black box model is used by data-driven methods, i.e., the Delta method $[16,17]$ and GPR-Delta [40]. A black-box model is created by training the network with input/output dataset. A well-trained black-box model, definition of stability and control derivative and the numerical perturbation of dimensionless force and moment coefficients are used for the parameter estimation. The equations defining the stability and control derivative with numerical perturbation is given at 16-18.

$$
\begin{aligned}
C_{L \alpha} & =\frac{\left(C L^{+}-C L^{-}\right)}{2 \Delta \alpha} \\
C m_{\alpha} & =\frac{\left(C m^{+}-C m^{-}\right)}{2 \Delta \alpha} \\
C_{D \alpha} & =\frac{\left(C D^{+}-C D^{-}\right)}{2 \Delta \alpha}
\end{aligned}
$$

The overall target is to demonstrate the capability of the proposed method in terms of accuracy and consistency related to other existing approaches for the parameter estimation. The approach includes comparing the estimates of all methods from simulated flight data (without and with random noise) and subsequently real flight data. The simulated flight data is contaminated with $5 \%, 10 \%$, and $15 \%$ of random noise. The comparative assessment of all longitudinal aerodynamic parameters by all methods mentioned earlier from simulated flight data (Without and with random noise) is presented in Tables 8-11.

\begin{tabular}{|c|c|c|c|c|c|c|c|c|c|c|c|}
\hline S.No & Para & $\begin{array}{l}\text { MLE (Gauss } \\
\text { Newton) }\end{array}$ & $\begin{array}{l}\text { Standard } \\
\text { deviation } \\
\text { (SD) } \\
\end{array}$ & $\begin{array}{l}\text { MLE } \\
\text { (Levenberg } \\
\text { Marquardt) }\end{array}$ & $\begin{array}{l}\text { Standard } \\
\text { deviation } \\
\text { (SD) } \\
\end{array}$ & ANN-delta & GPR-delta & $\begin{array}{l}\text { OEM } \\
\text { with GA }\end{array}$ & $\begin{array}{l}\text { Standard } \\
\text { deviation (SD) }\end{array}$ & $\begin{array}{l}\text { Standard } \\
\text { Error }\end{array}$ & $\mathbf{R 2}$ \\
\hline 1 & $\mathrm{C}_{\mathrm{D} 0}$ & 0.039972 & $1.38 \mathrm{E}-04$ & 0.039972 & $1.38 \mathrm{E}-04$ & ---- & ---- & 0.0399 & 0.0036 & 0.0008 & 0.9028 \\
\hline 2 & $\mathrm{C}_{\mathrm{D} \alpha}$ & 0.26091 & $3.37 \mathrm{E}-03$ & 0.26091 & 3.37E-03 & 0.260389 & 0.26914 & 0.2611 & 0.0033 & 0.0007 & 0.9252 \\
\hline 3 & $\mathrm{C}_{\mathrm{L} 0}$ & 0.2359 & $3.40 \mathrm{E}-04$ & 0.2359 & $3.40 \mathrm{E}-04$ & ---- & ---- & 0.2354 & 0.0325 & 0.0072 & 0.9124 \\
\hline 4 & $\mathrm{C}_{\mathrm{L} \alpha}$ & 5.28 & $8.47 \mathrm{E}-03$ & 5.28 & $8.47 \mathrm{E}-03$ & 5.855 & 5.159 & 5.2500 & 0.0274 & 0.0068 & 0.9358 \\
\hline 5 & $\mathrm{C}_{\mathrm{L} \delta \mathrm{e}}$ & 0.2078 & $2.02 \mathrm{E}-01$ & 0.2078 & $2.02 \mathrm{E}-01$ & 0.20691 & 0.20247 & 0.2072 & 0.0014 & 0.0003 & 0.8882 \\
\hline 6 & $\mathrm{C}_{\mathrm{m} 0}$ & 0.08024 & $1.07 \mathrm{E}-03$ & 0.08024 & $1.07 \mathrm{E}-03$ & ---- & ---- & 0.0803 & 0.0193 & 0.0043 & 0.9411 \\
\hline 7 & $\mathrm{C}_{\mathrm{m} \alpha}$ & -0.8771 & $1.23 \mathrm{E}-02$ & -0.8771 & $1.23 \mathrm{E}-02$ & -0.87631 & -0.87465 & -0.8676 & 0.0028 & 0.0006 & 0.8879 \\
\hline 8 & $\mathrm{C}_{\text {móe }}$ & -0.981 & $2.33 \mathrm{E}-02$ & -0.981 & 2.33E-02 & -0.11 & -0.98892 & -0.9879 & 0.0065 & 0.0015 & 0.9078 \\
\hline 9 & $\mathrm{C}_{\mathrm{mq}}$ & -5.8123 & $-5.83 \mathrm{E}+00$ & -5.8123 & $-5.83 E+00$ & ---- & ---- & 5.8156 & 0.2298 & 0.0530 & 0.7949 \\
\hline
\end{tabular}

\subsubsection{Comparison of Longitudinal Aerodynamic Parameters for ATTAS Aircraft (Simulated Flight Data)}

Table 8. Comparison of longitudinal parameters of ATTAS aircraft (Simulated - 0\%).

\begin{tabular}{|c|c|c|c|c|c|c|c|c|c|c|c|}
\hline S.No & Para & $\begin{array}{l}\text { MLE (Gauss } \\
\text { Newton) }\end{array}$ & $\begin{array}{l}\text { Standard } \\
\text { deviation } \\
\text { (SD) } \\
\end{array}$ & $\begin{array}{l}\text { MLE } \\
\text { (Levenberg } \\
\text { Marquardt) }\end{array}$ & $\begin{array}{l}\text { Standard } \\
\text { deviation } \\
\text { (SD) } \\
\end{array}$ & $\begin{array}{l}\text { ANN-delt } \\
\text { a }\end{array}$ & $\begin{array}{l}\text { GPR-delt } \\
\text { a }\end{array}$ & $\begin{array}{l}\text { OEM with } \\
\text { GA }\end{array}$ & $\begin{array}{l}\text { Standard } \\
\text { deviation } \\
\text { (SD) } \\
\end{array}$ & $\begin{array}{l}\text { Standard } \\
\text { Error }\end{array}$ & $\mathbf{R 2}$ \\
\hline 1 & $\mathrm{C}_{\mathrm{D} \alpha}$ & 0.26097 & $3.32 \mathrm{E}-03$ & 0.2610 & $3.32 \mathrm{E}-03$ & 0.2663 & 0.2691 & 0.2645 & 0.0042 & 0.0009 & 0.9067 \\
\hline 2 & $\mathrm{C}_{\mathrm{L} \alpha}$ & 5.282 & $8.48 \mathrm{E}-03$ & 5.282 & $8.48 \mathrm{E}-03$ & 5.3025 & 5.5642 & 5.2854 & 0.0568 & 0.0127 & 0.9358 \\
\hline 3 & $\mathrm{C}_{\mathrm{m} \alpha}$ & -0.8762 & $1.22 \mathrm{E}-02$ & -0.8762 & $1.22 \mathrm{E}-02$ & -0.8761 & -0.8776 & -0.8755 & 0.0059 & 0.0013 & 0.8773 \\
\hline
\end{tabular}

Table 9. Comparison of longitudinal parameters of ATTAS aircraft (Simulated - 5\%). 
Table 10. Comparison of longitudinal parameters of ATTAS aircraft (Simulated - 10\%).

\begin{tabular}{llllllllllll}
\hline S.No & Para & $\begin{array}{l}\text { MLE } \\
\text { (Gauss } \\
\text { Newton) }\end{array}$ & $\begin{array}{l}\text { Standard } \\
\text { deviation } \\
\text { (SD) }\end{array}$ & $\begin{array}{l}\text { MLE } \\
\text { (Levenberg } \\
\text { Marquardt) }\end{array}$ & $\begin{array}{l}\text { Standard } \\
\text { deviation } \\
\text { (SD) }\end{array}$ & $\begin{array}{l}\text { ANN-delt } \\
\text { a }\end{array}$ & GPR-delta & $\begin{array}{l}\text { OEM } \\
\text { with GA }\end{array}$ & $\begin{array}{l}\text { Standard } \\
\text { deviation } \\
\text { (SD) }\end{array}$ & $\begin{array}{l}\text { Standard } \\
\text { Error }\end{array}$ & R2 \\
\hline 1 & $\mathrm{C}_{\mathrm{D} \alpha}$ & 0.26093 & $2.85 \mathrm{E}-03$ & 0.26093 & $2.85 \mathrm{E}-03$ & 0.26424 & 0.26052 & 0.2666 & 0.0063 & 0.0014 \\
2 & $\mathrm{C}_{\mathrm{L} \alpha}$ & 5.2798 & $8.08 \mathrm{E}-03$ & 5.2798 & $8.08 \mathrm{E}-03$ & 5.446 & 5.47 & 5.4421 & 0.0776 & 0.0173 & 0.9112 \\
3 & $\mathrm{C}_{\mathrm{m} \alpha}$ & -0.87613 & $1.18 \mathrm{E}-02$ & -0.87613 & $1.18 \mathrm{E}-02$ & -0.85832 & -0.88123 & -0.8824 & 0.0073 & 0.0016 & 0.8821 \\
\hline
\end{tabular}

Table 11. Comparison of longitudinal parameters of ATTAS aircraft (Simulated-15\%).

\begin{tabular}{|c|c|c|c|c|c|c|c|c|c|c|c|}
\hline S.No & Para & $\begin{array}{l}\text { MLE } \\
\text { (Gauss } \\
\text { Newton) } \\
\end{array}$ & $\begin{array}{l}\text { Standard } \\
\text { deviation } \\
\text { (SD) } \\
\end{array}$ & $\begin{array}{l}\text { MLE } \\
\text { (Levenberg } \\
\text { Marquardt) }\end{array}$ & $\begin{array}{l}\text { Standard } \\
\text { deviation } \\
\text { (SD) } \\
\end{array}$ & ANN-delta & GPR-delta & $\begin{array}{l}\text { OEM } \\
\text { with GA }\end{array}$ & $\begin{array}{l}\text { Standard } \\
\text { deviation } \\
\text { (SD) } \\
\end{array}$ & $\begin{array}{l}\text { Standard } \\
\text { Error }\end{array}$ & $\mathbf{R}^{2}$ \\
\hline 1 & $\mathrm{C}_{\mathrm{D} \alpha}$ & 0.260924 & $3.14 \mathrm{E}-03$ & 0.260924 & $3.14 \mathrm{E}-03$ & 0.25273 & 0.27 & 0.2875 & 0.0053 & 0.0012 & 0.9013 \\
\hline 2 & $\mathrm{C}_{\mathrm{L} \alpha}$ & 5.2833 & $9.13 \mathrm{E}-03$ & 5.2833 & $9.13 \mathrm{E}-03$ & 5.2925 & 5.704 & 5.5100 & 0.0829 & 0.0185 & 0.9043 \\
\hline 3 & $\mathrm{C}_{\mathrm{m} \alpha}$ & -0.87642 & 1.19E-02 & -0.87642 & 1.19E-02 & -0.8223 & -0.82385 & -0.8398 & 0.0055 & 0.0012 & 0.8792 \\
\hline
\end{tabular}

The longitudinal aerodynamic parameters obtained from simulated flight data without noise exhibits that almost all aerodynamic parameters estimated by the proposed methodology are in rationally good agreement with the estimates from the ML method and other methods. The aerodynamic derivatives which are directly affected by the variation in motion and control variable are $\mathrm{C}_{\mathrm{D} \alpha}, \mathrm{C}_{\mathrm{L} \alpha}, \mathrm{C}_{\mathrm{m} \alpha}, \mathrm{C}_{\mathrm{L} \delta \mathrm{e}}$, and $\mathrm{C}_{\mathrm{m} \delta \mathrm{e}}$, and are known as strong aerodynamic derivatives. The magnitude of all strong aerodynamic derivatives, i.e., which greatly influence the longitudinal motion of the aircraft match well for all the methodologies including the proposed methodology. The reason for the consistent and well matching estimates exhibit the capability of the proposed methodology compared to other routines. The insignificant variation in the estimates can be accredited to the trivial constraint of the proposed method. Moreover, the simulated flight data might not be appropriate empowering improved parameter estimates. The underlying philosophy of data-driven methods is using numerical perturbation in motion and control variable for the parameter estimation so, the aerodynamic parameters viz. $\mathrm{C}_{\mathrm{D} 0}$, $\mathrm{C}_{\mathrm{L} 0} \& \mathrm{C}_{\mathrm{m} 0}$ are not estimated by Delta method $[16,17]$ and GPR-Delta [40] method. The estimates of longitudinal aerodynamic parameters affected by the presence of random noise $(5 \%, 10 \% \& 15 \%)$ in the angle of attack too continue to be in fair agreement with the estimates from ML method and other data-driven methods.

\subsubsection{Comparison of Longitudinal Aerodynamic \\ Parameters for ATTAS Aircraft (Real Flight Data)}

As mentioned earlier, that same real flight data is employed by other methods for parameter estimation, which was utilized by the proposed GA optimized output error method. Table 12 presents the comparison of longitudinal aerodynamic parameters for ATTAS aircraft considered in present work. The comparative assessment of aerodynamic parameters aims to establish that the proposed method can adequately handle the real flight data for parameter estimation similarly as all other renowned methods handle.

Table 12. Comparison of longitudinal parameters of ATTAS aircraft (Real flight data).

\begin{tabular}{|c|c|c|c|c|c|c|c|c|c|c|c|}
\hline S.No & Para & $\begin{array}{l}\text { MLE } \\
\text { (Gauss } \\
\text { Newton) }\end{array}$ & $\begin{array}{l}\text { Standard } \\
\text { deviation } \\
\text { (SD) } \\
\end{array}$ & $\begin{array}{l}\text { MLE } \\
\text { (Levenberg } \\
\text { Marquardt) }\end{array}$ & $\begin{array}{l}\text { Standard } \\
\text { deviation } \\
\text { (SD) } \\
\end{array}$ & $\begin{array}{l}\text { ANN-delt } \\
\text { a }\end{array}$ & $\begin{array}{l}\text { GPR-delt } \\
\text { a }\end{array}$ & $\begin{array}{l}\text { OEM } \\
\text { with GA }\end{array}$ & $\begin{array}{l}\text { Standard } \\
\text { deviation } \\
\text { (SD) } \\
\end{array}$ & $\begin{array}{l}\text { Standard } \\
\text { Error }\end{array}$ & $\mathbf{R}^{2}$ \\
\hline 1 & $\mathrm{C}_{\mathrm{D} 0}$ & 0.03995 & $1.36 \mathrm{E}-04$ & 0.03995 & $1.36 \mathrm{E}-04$ & ---- & ---- & 0.0408 & 0.0036 & 0.0008 & 0.9200 \\
\hline 2 & $\mathrm{C}_{\mathrm{D} \alpha}$ & 0.26097 & 3.37E-03 & 0.26097 & $3.37 \mathrm{E}-03$ & 0.260389 & 0.26914 & 0.2613 & 0.0033 & 0.0007 & 0.9043 \\
\hline 3 & $\mathrm{C}_{\mathrm{L} 0}$ & 0.2354 & $3.40 \mathrm{E}-04$ & 0.2354 & $3.40 \mathrm{E}-04$ & ---- & ---- & 0.2352 & 0.0323 & 0.0072 & 0.9243 \\
\hline 4 & $\mathrm{C}_{\mathrm{L} \alpha}$ & 5.225 & $8.42 \mathrm{E}-03$ & 5.225 & $8.42 \mathrm{E}-03$ & 5.855 & 5.159 & 5.2625 & 0.0274 & 0.0613 & 0.9425 \\
\hline 5 & $\mathrm{C}_{\mathrm{L} \delta \mathrm{e}}$ & 0.2072 & $2.07 \mathrm{E}-01$ & 0.2072 & 2.07E-01 & 0.20691 & 0.20247 & 0.2068 & 0.0137 & 0.0031 & 0.8518 \\
\hline 6 & $\mathrm{C}_{\mathrm{m} 0}$ & 0.08032 & $1.07 \mathrm{E}-03$ & 0.08032 & $1.07 \mathrm{E}-03$ & ---- & ---- & 0.0809 & 0.0193 & 0.0043 & 0.9691 \\
\hline 7 & $\mathrm{C}_{\mathrm{m} \alpha}$ & -0.8776 & $1.29 \mathrm{E}-02$ & -0.8776 & $1.29 \mathrm{E}-02$ & -0.87631 & -0.8747 & -0.8724 & 0.0281 & 0.0063 & 0.9127 \\
\hline 8 & $\mathrm{C}_{\text {mסe }}$ & -0.984 & $2.34 \mathrm{E}-02$ & -0.984 & $2.34 \mathrm{E}-02$ & -0.11 & -0.9889 & -0.9821 & 0.0652 & 0.0146 & 0.9298 \\
\hline 9 & $\mathrm{C}_{\mathrm{mq}}$ & -5.8198 & $-5.82 \mathrm{E}+00$ & -5.8198 & $-5.82 \mathrm{E}+00$ & ---- & ---- & 5.8017 & 0.2372 & 0.5304 & 0.6548 \\
\hline
\end{tabular}

The longitudinal aerodynamic parameters as obtained from real flight data evidence that, the estimates made with real flight data exists in decent agreement with the estimates from the ML method and other methods. The aerodynamic derivatives which are affected by the change in motion and control variable are found to be in respectable agreement with the estimates from other methodologies. The reliable and matching estimates reveal the capability of the projected procedure for the determination of aerodynamic derivatives. The quality of flight data is another crucial factor for the excellence of estimates by any methodology. The ML method uses the gradient-based optimization strategy for parameter vector update. The success of any gradient-based optimization strategy relies on the quality of the computed first and second gradients. The data-driven methods entirely depend upon the training of the network for the quality of the estimates. A well-trained network is the outcome of optimally selected network training parameters like learning rate, momentum term, and the number of neurons, etc. 
The success of the genetic algorithm depends on the quality of search space, proper selection of tuning parameters like cross-over fraction, the crossover point and quantum of mutation, etc. The minor deviation in the parameter estimates is due to the different functioning of various methodologies. It is imperative to mention again that the data-driven methods employ numerical perturbation in the motion and control variable and the definition of stability and control derivative for parameter estimation. Therefore some of the aerodynamic parameters such as $\mathrm{C}_{\mathrm{D} 0}, \mathrm{C}_{\mathrm{L} 0} \& \mathrm{C}_{\mathrm{m} 0}$ are not estimated by both data-driven methods.

\section{Conclusions}

In the present work, the genetic algorithm optimized output error method is employed for the estimation of the longitudinal aerodynamic parameters of the aircraft. The proposed method is applied on simulated flight data (Without noise and with random noise) and real flight data. The real flight data of ATTAS aircraft is obtained from open access source. The selected flight data corresponds to the flight maneuver executed for the excitation of the longitudinal modes of the aircraft. The corresponding measured motion and control variables along with derived aerodynamic force and moments were separated as the valuable input-output data. The aerodynamic parameters were estimated along with their statistical analysis for an enhanced understanding of the parameter estimates. The longitudinal aerodynamic parameters were compared with the parameter estimates obtained from the Maximum-Likelihood method, Delta method [16, 17] and GPR-Delta [40] method. The estimated parameters obtained by using the proposed GA optimized output error method were observed to be in decent agreement with the estimates obtained from other existing methods. The estimates exhibited a small magnitude of standard deviation and hence small magnitude of the standard error. The parameter estimates have shown a high value of the coefficient of determination $\left(\mathrm{R}^{2}\right)$, which enables the boosting of confidence on the parameter estimates.

The estimated longitudinal aerodynamic parameters evidence that the GA optimized output error method can be a potentially viable methodology for the aerodynamic parameter estimation using flight data. The proposed methodology can be further applied to other problems of parameter estimation viz. lateral-directional parameter estimation, longitudinal parameter estimation at a high angle of attack, real-time monitoring, and estimation of aerodynamic parameters, and many more similar applications.

\section{Nomenclature}

The Following symbols are used in this paper:

$a_{X}$
$a_{Z}$
$\mathrm{~b}$
$C_{L 0}$
$C_{D 0}$
$C_{m 0}$
$C_{D \alpha}$
$C_{L \alpha}$
$C_{L q}$
$C_{m \alpha}$
$C_{L \delta e}$
$C_{m \delta e}$
$C_{m q}$
$C_{X}$
$C_{Z}$
$\overline{\mathrm{q}}$
$\mathrm{S}_{\text {ref }}$
$\mathrm{T}$
$\mathrm{V}$
$\mathrm{m}$
$\mathrm{Y}$
$Y_{c o s t}$
$\mathrm{Z}$
$\mathrm{e}$
$\gamma$
$\alpha$
$\Phi$
$\Theta$
$\delta \mathrm{e}$

Acceleration along the $\mathrm{X}$ axis

Acceleration along the $\mathrm{Z}$ axis

Full wingspan, $\mathrm{m}$

Dimensionless lift coefficient at zero angle of attack

Dimensionless drag coefficient at zero angle of attack

Dimensionless pitching moment coefficient at zero angle of attack

Dimensionless slope of drag coefficient Vs. angle of attack

Dimensionless slope of lift Vs. angle of attack curve

Variation of dimensionless lift coefficient with pitch rate

Dimensionless slope of moment coefficient Vs. angle of attack curve

Dimensionless slope of lift coefficient Vs. elevator deflection curve

Dimensionless slope of moment coefficient Vs. elevator deflection curve

Variation of dimensionless moment coefficient with pitch rate

Non-dimensional force in $\mathrm{X}$ - axis (Force acting forward is $+\mathrm{ve}$ )

Non-dimensional force in $\mathrm{Z}$ - axis (Force acting downwards is $+\mathrm{ve}$ )

Dynamic pressure, $\mathrm{N} / \mathrm{m}^{2}$

Reference wing area, $\mathrm{m} 2$

Twin engine thrust, $\mathrm{N}$

True airspeed, $\mathrm{m} / \mathrm{s}$

Mass of aircraft, $\mathrm{Kg}$

Estimated value of the response variable

Cost function for minimization

Measured value of the response variable

Response error between measured and estimated response variable

Flight path angle

Angle of attack, deg

Ground effect factor

Pitch angle, deg

Elevator deflection angle, deg 


\section{References}

[1] JATEGAONKAR, R. V., "Flight Vehicle System Identification: A Time Domain Methodology," AIAA Education Series, AIAA, Reston, VA, 2006.

[2] MEHRA, RAMAN, K., "Maximum likelihood identification of aircraft parameters." Joint Automatic Control Conference. No. 8, 1970.

[3] HAMEL, P. G., AND JATEGAONKAR, R. V., "The Evolution of Flight Vehicle System Identification," AGARD, DLR Germany, $8 \cdot 10$, May 1995 .

[4] ROSKAM, J., "Methods for Estimating Stability and Control Derivatives for conventional Subsonic Airplanes," Roskam Aviation and Engineering Corporation, 1973

[5] ILIFF, K. W., "Parameter Estimation for Flight Vehicle," Journal of Guidance, Control and Dynamics, Vol. 12, No. 5, 1989, pp 609-622

[6] HAMEL, P. G., "Aircraft Parameter Identification Methods and their Applications Survey and Future Aspect," AGARD, 13-104, Nov. 1979, Paper 1.

[7] KLEIN, V., AND MORELLI, E. A., "Aircraft system identification-Theory and practice," AIAA Education Series, Reston, VA, 2006.

[8] RAOL R., JITENDRA, AND SINGH, J., "Flight Mechanics Modeling and Analysis," CRC Press, Taylor and Francis Group, 2009.

[9] MAINE, K. E., AND ILIFF, K. W., “Application of Parameter Estimation to Aircraft Stability and Control: The Output Error Approach,” NASA RP 1168, Jan. 1986.

[10] MILLIKEN, W. F. JR., "Progress in Dynamic Stability and Control Research," Journal of the Aeronautical Sciences, Vol. 14, No. 9, 1947, pp. 493-519.

[11] GREENBERG, H., "A Survey of Methods for Determining Stability Parameters of an Airplane from Dynamic Flight Measurements," NACA TN-2340, April 1951.

[12] SHINBROT, M., "A Least square Curve Fitting Method with Applications to the Calculation of Stability Coefficients from Transient Response Data," NACA TN 2341, April 1951.

[13] MAINE, R. E. AND ILIFF, K. W. "Formulation and Implementation of a Practical Algorithm for Parameter Estimation with Process and Measurement Noise," Society for Industrial and Applied Mathematics, Journal of Applied Mathematics, Vol. 41, Dec. 1981, pp. 558-579.

[14] BALAKRISHNAN, A. V., "Stochastic System Identification Techniques," in Stochastic Optimization and Control, edited by H. F. Karreman, John Wiley and Sons, London, 1968.

[15] RAOL, J. R., and JATEGAONKAR, R. V., "Aircraft Parameter Estimation using Recurrent Neural Networks- A Critical Appraisal," A1AA Paper 95-3004, Aug. 1995.

[16] RAISINGHANI, S. C., GHOSH, A. K., and KALRA, P. K., "Two New Techniques for Aircraft Parameter Estimation Using Neural Networks," The Aeronautical Journal, Vol. 102, No. 1011, Jan. 1998, pp. 25-29.
[17] GHOSH, A. K., RAISINGHANI, S. C., and KHUBCHANDANI, S., "Estimation of Aircraft Lateral-Directional Parameters using Neural Networks," Journal of Aircraft, Vol. 35, No. 6, Nov.-Dec. 1998, pp. 876-881.

[18] SINGH, S., "Estimation of Aircraft Parameters from Flight Data using Neural Network-Based Method," Ph. D. Thesis, Aerospace Engineering Dept., IIT Kanpur, April 2007.

[19] PEYADA, N. K., and GHOSH, A. K., "Aircraft Parameter Estimation using New Filtering Technique based on Neural Network and Gauss-Newton Method," Aeronautical Journal, UK, Vol. 113, No. 1142, April 2009.

[20] PEYADA, N. K., and GHOSH, A. K., "Parameter Estimation from Real Flight Data using Neural Network based Method," INCPAA- 2008, Mathematical Problems in Engineering, Aerospace and Sciences, University of Genoa, Italy, June 25-27, 2008.

[21] KUMAR, R., and GHOSH, A. K., "Nonlinear Longitudinal Aerodynamic Modeling using Quasi-steady Stall Model and Neural Gauss-Newton Method," Journal of Aircraft, AIAA, USA, Vol. 48, No. 5, Sept.-Oct. 2011, pp. 1809-1812.

[22] KUMAR, R., and GHOSH, A. K., "Nonlinear Aerodynamic Modeling of Hansa-3 Aircraft using Neural Gauss-Newton Method," Journal of Aerospace Sciences and Technologies, AeSI, India, Vol. 63, No. 3, August 2011, pp. 194-204.

[23] NELLES, O., “ Nonlinear System Identification From Classical Approaches to Neural Networks and Fuzzy Models, Springer-Vwrlag Berlin Heidelberg, 2001.

[24] KUMAR, A., and GHOSH, A. K., "ANFIS-Delta Method for Aerodynamic Parameter Estimation using Flight Data," Proceedings of the Institution of Mechanical Engineers, Part G: Journal of Aerospace Engineering, 2018

[25] KUMAR, A., and GHOSH, A. K., "Decision Tree and Random Forest Methods Based Novel Unsteady Aerodynamics Modeling Using Flight Data," Journal of Aircraft. 2018 Sep: 1-7.

[26] KUMAR, A., and GHOSH, A. K, "A GPR Based Novel Approach for Aerodynamic Parameter Estimation from Flight Data," International Review of Aerospace Engineering, 2018

[27] KUMAR, A., and GHOSH, A. K., "GPR based Novel Approach for Nonlinear Aerodynamic Modeling from Flight Data," The Aeronautical Journal, 2018, pp 1-14.

[28] SIMON, D., "Evolutionary optimization algorithms," John Wiley \& Sons, 2013.

[29] MITCHELL, M., "An Introduction to genetic algorithms," MIT Press, 1998.

[30] HOLLAND, J. H., "Genetic algorithms," Scientific American, 267 (1), 66-73, 1992.

[31] HOLLAND, J. H., and GOLDBERG, D., "Genetic algorithms in search, optimization and machine learning," Massachusetts: Addison-Wesley, 1989.

[32] NEJATI, V., and MATSUUCHI, K., "Aerodynamics design and genetic algorithms for optimization of airship bodies," JSME International Journal Series B Fluids and Thermal Engineering., 46 (4), 610-617, 2003. 
[33] ALlAiRe, F. C., TARBOUCHI, M., LABONTÉ, G., and FUSINA, G., "FPGA implementation of genetic algorithm for UAV real-time path planning in Unmanned Aircraft Systems." Springer, Dordrecht, 495-510, 2008.

[34] HE, Y., QU, Q., and AGARWAL, R. K., "Shape Optimization of an Aerofoil in Ground effect for Application to WIG Craft." 53rd AIAA Aerospace Sciences Meeting, 0758, 2015.

[35] LEE, J., HONG, C. H., KIM, B. S., PARK, K., and AHN, J., "Optimization of wings in ground effect using multi-objective genetic algorithm" 48th AIAA Aerospace Sciences Meeting Including the New Horizons Forum and Aerospace Exposition, 1422, January 2010.

[36] LEE, S. H., and LEE, J., "Optimization of three-dimensional wings in ground effect using multi-objective genetic algorithm" Journal of Aircraft., 48 (5), 1633-1645, 2011.

[37] LI, S., ZHOU, D., ZHANG, Y., and QU, Q., “Aerodynamic investigation of RAE2822 aerofoil in ground effect" Procedia Engineering., 126, 174-178, 2015.

[38] MAGRINI, A., and BENINI, E., “Aerodynamic Optimization of a Morphing Leading Edge Aerofoil with a Constant Arc Length Parameterization" Journal of Aerospace Engineering. 31 (2), 04017093, 2017.

[39] KALE, S., JOSHI, P., and PANT, R., "A generic methodology for determination of drag coefficient of an aerostat envelope using CFD." AIAA 5th ATIO and 16th Lighter-Than-Air Sys Tech. And Balloon Systems Conference, 7442, September 2005.

[40] KUMAR, A., "Machine Learning Methods for Aerodynamic Modelling and Parameter Estimation," Ph. D. Thesis, Aerospace Engineering Dept., IIT Kanpur, Jan 2018.

[41] NAPOLITANO R. M., "Aircraft Dynamics -From Modelling to Simulation," 1st Edition, Wiley, November 2011. 